\title{
The Good, the Bad, and the Techy (Scaled as Appropriate)
}

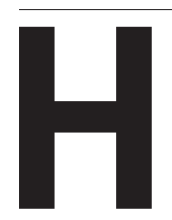

$\mathrm{CI}$ and interaction design

(IxD) have always brought challenges. As some are met, others arise. For example, as devices, users, contexts, and computational capabilities proliferate, scaling becomes a key challenge. The cover story by Barry Brown, Susanne Bødker, and Kristina Höök discusses how HCI scales (or doesn't) across numbers of users, contexts of use, and multitudes of systems and technologies. The authors propose four hacks to deal with scaling issues, while cautioning us that hacks are a limited solution.

Steven Houben and colleagues focus on challenges and future opportunities for cross-device interactions. Albrecht Schmidt and Thomas Herrmann add to this issue's focus on scaling challenges by discussing appropriate user control as automation comes to dominate interaction. Similarly, each day the Urban Complexity Lab addresses complex data analysis and visualization, especially for digital humanities and smart cities. In the world of practice, these interweaving complexities must be managed, creating challenges that Elizabeth Churchill addresses in Ps and Qs. The Business of UX forum makes it clear that bad advice here is not uncommon. We need new research, management, and education to face increasingly complex IxD challenges. Community Square shares SIGCHI's current educational initiatives.

Whatever the focus or perspective, scaling must bring better futures. As with any design discipline, IxD and underpinning $\mathrm{HCI}$ research require judgment. At times, only a magic wand appears to have any chance of delivering on all desirable goods while diminishing all bads. We have thus "scaled up" our Confessions column to a new focus, Abracadabra. m.c. schraefel is the first to wave her wand, turning us from preventing disease to enhancing our bodies' performance, with the challenge of creating what she calls wellth at scale. In their feature, Markéta Dolejšová and Tereza Lišková bring the Czech Republic to Interactions, showing how "narrative sauces" can be derived from stories by homeless chefs, who can then share their stories with bistro visitors in unique opportunities for face-toface conversation. This scales critical speculative design to concrete socially aware services. Other forms of good are more familiar, with exercise made more accessible in the Health Matters forum. Finally, what's good or not is open to debate in HCI. Thus, two forums in this issue respectively take critical positions on sustainability and $\mathrm{HCI}$ for development (HCI4D).

As designers and their supporters, we must increase the good and avoid the bad. Deborah Tatar's recent (re)readings warn us about the dangerous effects of scale in data-crunching systems that prompt us to make decisions about individuals based on group predictions, and other opaque technologies that somehow gain our trust and nudge our behavior. Similarly, Jonathan Bean and Melanie Wallendorf discuss the unease caused by payment systems that make us decide a tip before receiving service, undermining a tip as a reward. Lassi Liikkanen discusses data-driven design from a Web interaction design perspective, focusing on methods and challenges of data collection, as well as the ethics of passive tracking.

Uday Gajendar's four interacting forces of interaction are domains of impact, technological marvels, business creation, and existential value. Too often, extremes of user-centeredness corral all good into domains of usage, devaluing business, designer, and engineering perspectives. All are sources of both good and bad. None is inherently ugly.

In our recent survey of Interactions readers, keeping up to date with interactive technologies and approaches was a top priority. We thus also celebrate the "techy" in this issue. Stefanie Mueller's forum provides a short tutorial on 3D printing, a source of new IxD opportunities. And as techy spans both the aesthetic and the technical, Maria Luce Lupetti's Blog@ IX considers good and bad design sensibilities for a robot in a heritage context. As ever, Demo Hour and How Was It Made address aesthetic and technical concerns, as does the Visual Thinking Gallery, which is the last to be curated by Eli Blevis after several years of service to Interactions. We thank Eli for his significant contributions to the visual focus of Interactions and the enduring foundations from which we all now benefit as editors and readers.

Gilbert Cockton and Simone Barbosa eic@interactions.acm.org 